\title{
PELABELAN FUZZY PADA GRAF
}

\author{
Siti Rahmah Nurshiami, Suroto, dan Fajar Hoeruddin \\ Universitas Jenderal Soedirman \\ email : oeytea10@gmail.com
}

\begin{abstract}
This paper discusses fuzzy labeling graph and its properties. The properties discussed are fuzzy labeling subgraph, union graph, and fuzzy magic graph. The results showed that the strength of connectedness for pair of vertices in a graph with fuzzy labeling is always greater than or equal to the strength of connectedness for pair of vertices in its subgraph. In addition, union of two graph with fuzzy labeling will form a graph with fuzzy labeling. Meanwhile, on magic labeling there is always a fuzzy bridge on fuzzy magic graph.
\end{abstract}

Keywords: Fuzzy labeling, fuzzy bridge, fuzzy magic graph

ABSTRAK. Pada makalah ini, dibahas pelabelan fuzzy dan sifatnya. Sifat terkait yang dibahas pada makalah ini adalah pelabelan fuzzy subgraf, gabungan dua graf, dan graf ajaib fuzzy. Hasil menunjukkan bahwa kekuatan keterhubungan sepasang simpul pada sebuah graf dengan label fuzzy selalu lebih besar atau sama dengan kekuatan keterhubungan sepasang simpul tersebut di subgrafnya. Selain itu, gabungan dua graf dengan label fuzzy akan membentuk sebuah graf dengan pelabelan fuzzy. Sementara itu, pada pelabelan yang bersifat ajaib selalu terdapat jembatan fuzzy pada graf ajaib fuzzy.

Kata kunci: Pelabelan fuzzy, jembatan fuzzy, graf ajaib fuzzy

\section{PENDAHULUAN}

Perkembangan ilmu pengetahuan tidak pernah terlepas dari peran serta matematika sebagai alat untuk berbagai ilmu pengetahuan. Hal ini disebabkan karena matematika dapat diaplikasikan dalam bidang disiplin ilmu lain dalam mengatasi permasalahan baik dalam bentuk perumusan, logika, pemodelan dan metode matematika lainnya. Salah satu pokok bahasan dari matematika yang memiliki banyak terapan sampai saat ini adalah teori graf. Dalam bidang kajian ilmu matematika, graf merepresentasikan objek-objek diskrit dan hubungan antara objekobjek tersebut. Representasi visual dari graf adalah dengan menyatakan objek sebagai simpul, sedangkan hubungan di antara objek dinyatakan dengan sisi. 
Seiring perkembangannya, banyak teori yang berkaitan dengan graf diperkenalkan sebagai penemuan baru. Salah satu yang menjadi perhatian baru dewasa ini adalah tentang teori graf fuzzy yang merupakan pengembangan dari konsep himpunan fuzzy dan graf klasik. Sejarah perkembangan himpunan fuzzy dimulai pada tahun 1965 oleh Lotfi A. Zadeh yang mengangkat tentang fenomena ketidakpastian pada situasi kehidupan nyata yang dijelaskan dalam kerangka matematis. Teori ini lahir akibat banyaknya permasalahan yang tidak bisa diselesaikan hanya dengan himpunan tegas, karena tidak semua himpunan yang dijumpai dalam kehidupan sehari-hari terdefinisi secara jelas, misalnya himpunan orang miskin, himpunan orang pandai, himpunan orang tinggi, dan sebagainya. Kemudian, Bede (2013) mendefinisikan himpunan fuzzy sebagai suatu fungsi yang memetakan semua elemen semestanya ke dalam interval tutup $[0,1]$.

Selanjutnya menurut Sunitha (2001), pada tahun 1973 Kaufmann memperkenalkan gagasan tentang definisi graf fuzzy yang didasarkan pada relasi fuzzy yang dikembangkan oleh Zadeh. Definisi yang lebih terperinci diberikan oleh Rosenfeld pada tahun 1975 yang mendefinisikan sebuah graf fuzzy dengan himpunan simpul fuzzy dan himpunan sisi fuzzy. Seiring dengan semakin banyaknya penelitian tentang graf fuzzy maka konsep-konsep dasar teori graf fuzzy banyak ditemukan sebagai hasil generalisasi dari teori graf. Di antaranya penelitian yang dilakukan oleh Gani dan Subahashini (2012) dan Gani, dkk (2014) mengenai pelabelan fuzzy pada suatu graf. Dalam makalah ini akan dibahas mengenai pelabelan fuzzy pada suatu graf beserta sifatnya.

\section{METODE PENELITIAN}

Metode yang digunakan adalah studi literatur mengenai definisi pelabelan fuzzy yang telah dikaji oleh Gani dan Subahashini (2012). Adapun langkahlangkah dalam melakukan pelabelan fuzzy pada sebuah graf dasar $G$ adalah dengan memberikan fungsi bijektif $\sigma^{\omega}$ yang memetakan seluruh himpunan simpul ke himpunan $A \subseteq[0,1]$ dan fungsi bijektif $\mu^{\omega}$ yang memetakan seluruh himpunan sisi ke himpunan $B \subseteq[0,1]$. Selanjutnya, diberikan proposisi dan sifat 
yang berkaitan dengan pelabelan fuzzy dan contohnya. Dalam penelitian ini juga dibahas mengenai pelabelan fuzzy ajaib beserta sifat dan contohnya.

\section{HASIL DAN PEMBAHASAN}

Definisi 1. Misal $V$ adalah himpunan simpul tak kosong dan E adalah himpunan sisi pada graf $G^{*}(V, E)$. Pelabelan fuzzy adalah fungsi bijektif $\sigma^{\omega}$ dan $\mu^{\omega}$, dengan $\sigma^{\omega}$ memetakan simpul di $G^{*}$ ke $A \subseteq[0,1]$ dan $\mu^{\omega}$ memetakan sisi di $G^{*}$ ke $B \subseteq[0,1]$ sedemikian sehingga nilai fungsinya berbeda untuk semua titik dan sisi, serta memenuhi $\mu^{\omega}(u, v)<\sigma^{\omega}(u) \wedge \sigma^{\omega}(v)$ untuk setiap $u, v \in V$.

Contoh Misal diberikan graf $G^{*}(V, E)$ dengan $V=\left\{v_{1}, v_{2}, v_{3}, v_{4}\right\}$ dan $E=\left\{\left(v_{1}, v_{2}\right),\left(v_{1}, v_{3}\right),\left(v_{2}, v_{3}\right),\left(v_{3}, v_{4}\right),\left(v_{1}, v_{4}\right)\right\}$. Selanjutnya, diberikan fungsi bijektif $\sigma^{\omega}$ dan $\mu^{\omega}$ yang mengaitkan setiap simpul $v_{x}$ di $G^{*}$ dengan fungsi $\sigma^{\omega}\left(v_{x}\right)=\frac{1}{2 x}$ dan $\mu^{\omega}\left(v_{x}, v_{y}\right)=\frac{1}{\left(x^{2}+y^{2}\right)}$. Graf $G^{\omega}=\left(\sigma^{\omega}, \mu^{\omega}\right)$ yang merupakan hasil pelabelan fuzzy dari graf $G^{*}$ dapat direpresentasikan dalam Gambar 1 .

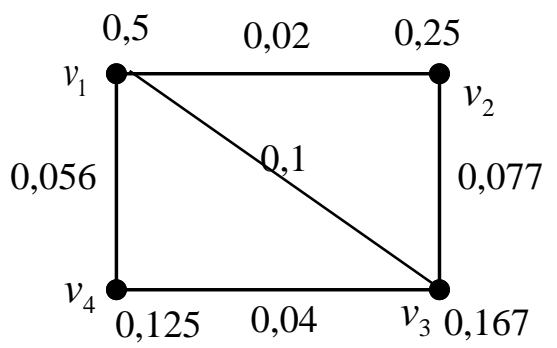

Gambar 1 Graf $G^{\omega}=\left(\sigma^{\omega}, \mu^{\omega}\right)$ 
Definisi 2. Misalkan graf $G^{\omega}=\left(\sigma^{\omega}, \mu^{\omega}\right)$ adalah graf dengan pelabelan fuzzy. Graf $H^{\omega}=\left(\tau^{\omega}, \rho^{\omega}\right)$ disebut subgraf dengan pelabelan fuzzy dari $G^{\omega}$ jika memenuhi $\tau^{\omega}(u) \leq \sigma^{\omega}(u)$ untuk setiap $u \in V$ dan $\rho^{\omega}(u, v) \leq \mu^{\omega}(u, v)$ untuk setiap $u, v \in V$.

Proposisi 3. Jika $H^{\omega}=\left(\tau^{\omega}, \rho^{\omega}\right)$ adalah subgraf dengan pelabelan fuzzy dari $G^{\omega}=\left(\sigma^{\omega}, \mu^{\omega}\right)$ maka $\rho^{\omega^{\infty}}(u, v) \leq \mu^{\omega^{\infty}}(u, v)$ untuk setiap $u, v \in V$.

Bukti. Misalkan $G^{\omega}=\left(\sigma^{\omega}, \mu^{\omega}\right)$ adalah sembarang graf dengan pelabelan fuzzy dan $H^{\omega}=\left(\tau^{\omega}, \rho^{\omega}\right)$ adalah subgraf dengan pelabelan fuzzy dari $G^{\omega}$ sehingga berlaku $\rho^{\omega}(u, v) \leq \mu^{\omega}(u, v)$ untuk setiap $u, v \in V$. Ambil sembarang lintasan di $H^{\omega}$ yang menghubungkan titik $u$ dan $v$ dengan panjang lintasan $n$ misalkan lintasan $\ell(u-v)=u, v_{1}, v_{2}, \ldots, v_{n-1}, v$. Kekuatan keterhubungan diantara dua titik $u$ dan $v$ dapat dirumuskan sebagai

$$
\rho^{\omega^{\infty}}(u, v)=\sup \left\{\rho^{\omega^{k}}(u, v) \mid k=1,2,3, \ldots n\right\}
$$

dengan

$$
\rho^{\omega^{k}}(u, v)=\sup \left\{\left(\rho^{\omega}\left(u, v_{1}\right) \wedge \rho^{\omega}\left(v_{1}, v_{2}\right) \wedge \rho^{\omega}\left(v_{2}, v_{3}\right) \wedge \ldots \wedge \rho^{\omega}\left(v_{k-1}, v\right)\right)\right\},
$$

disebut kekuatan lintasan dengan panjang $k$. Perhatikan kembali bahwa untuk sembarang titik $u$ dan $v$ berlaku $\rho^{\omega}(u, v) \leq \mu^{\omega}(u, v)$ sehingga diperoleh

$$
\begin{gathered}
\rho^{\omega}\left(u, v_{1}\right) \leq \mu^{\omega}\left(u, v_{1}\right), \\
\rho^{\omega}\left(v_{1}, v_{2}\right) \leq \mu^{\omega}\left(v_{1}, v_{2}\right), \\
\rho^{\omega}\left(v_{2}, v_{3}\right) \leq \mu^{\omega}\left(v_{2}, v_{3}\right), \\
\vdots \\
\rho^{\omega}\left(v_{n-1}, v\right) \leq \mu^{\omega}\left(v_{n-1}, v\right) .
\end{gathered}
$$

Akibatnya,

$$
\rho^{\omega}\left(u, v_{1}\right) \wedge \rho^{\omega}\left(v_{1}, v_{2}\right) \wedge \ldots \wedge \rho^{\omega}\left(v_{n-1}, v\right) \leq \mu^{\omega}\left(u, v_{1}\right) \wedge \mu^{\omega}\left(v_{1}, v_{2}\right) \wedge \ldots \wedge \mu^{\omega}\left(v_{n-1}, v\right) .
$$


Selanjutnya,

$$
\begin{aligned}
\rho^{\omega^{k}}(u, v) & =\sup \left\{\rho^{\omega}\left(u, v_{1}\right) \wedge \rho^{\omega}\left(v_{1}, v_{2}\right) \wedge \rho^{\omega}\left(v_{2}, v_{3}\right) \wedge \ldots \wedge \rho^{\omega}\left(v_{k-1}, v\right)\right\} \\
& \leq \sup \left\{\mu^{\omega}\left(u, v_{1}\right) \wedge \mu^{\omega}\left(v_{1}, v_{2}\right) \wedge \mu^{\omega}\left(v_{2}, v_{3}\right) \wedge \ldots \wedge \mu^{\omega}\left(v_{k-1}, v\right)\right\} \\
& =\mu^{\omega^{k}}(u, v)
\end{aligned}
$$

Kemudian, dengan mensubtitusikan pertidaksamaan $\rho^{\omega^{k}}(u, v) \leq \mu^{\omega^{k}}(u, v) \quad \mathrm{ke}$ persamaan (1) diperoleh

$$
\begin{aligned}
\rho^{\omega^{\infty}}(u, v) & =\sup \left\{\rho^{\omega^{k}}(u, v) \mid k=1,2,3, \ldots\right\} \\
& \leq \sup \left\{\mu^{\omega^{k}}(u, v) \mid k=1,2,3, \ldots\right\} \\
& =\mu^{\omega^{\infty}}(u, v)
\end{aligned}
$$

Jadi, terbukti bahwa untuk setiap $u, v \in V$ berlaku $\rho^{\omega^{\infty}}(u, v) \leq \mu^{\omega^{\infty}}(u, v)$.

Proposisi 4. Gabungan dari dua graf dengan label fuzzy $G_{1}^{\omega}$ dan $G_{2}{ }^{\omega}$ merupakan graf dengan pelabelan fuzzy, jika nilai fungsi untuk setiap simpul dan sisi $G_{1}^{\omega}$ dan $G_{2}{ }^{\omega}$ berbeda.

Bukti. Misal $G_{1}^{\omega}=\left(\sigma_{1}^{\omega}, \mu_{1}^{\omega}\right)$ dan $G_{2}{ }^{\omega}=\left(\sigma_{2}{ }^{\omega}, \mu_{2}{ }^{\omega}\right)$ adalah dua graf dengan pelabelan fuzzy yang memiliki nilai fungsi berbeda untuk setiap sisi antara $G_{1}^{\omega}$ dan $G_{2}{ }^{\omega}$. Dengan demikian, $\sigma_{1}^{\omega}\left(u_{1}\right) \neq \sigma_{2}{ }^{\omega}\left(u_{2}\right), \sigma_{1}^{\omega}\left(u_{1}\right) \neq \mu_{2}{ }^{\omega}\left(u_{2}, v_{2}\right)$, $\mu_{1}^{\omega}\left(u_{1}, v_{1}\right) \neq \sigma_{2}^{\omega}\left(u_{2}\right), \quad$ dan $\mu_{1}^{\omega}\left(u_{1}, v_{1}\right) \neq \mu_{2}^{\omega}\left(u_{2}, v_{2}\right)$ untuk setiap $u_{1}, v_{1} \in V_{1}$ dan $u_{2}, v_{2} \in V_{2}$. Gabungan dari $G_{1}^{\omega}$ dan $G_{2}{ }^{\omega}$ adalah graf $G^{\omega}=\left(\sigma^{\omega}, \mu^{\omega}\right)$ dengan

$$
\sigma^{\omega}=\left(\sigma_{1}^{\omega} \cup \sigma_{2}^{\omega}\right)(x)= \begin{cases}\sigma_{1}^{\omega}(x), & \text { untuk } x \in V_{1}-V_{2} \\ \sigma_{2}{ }^{\omega}(x), & \text { untuk } x \in V_{2}-V_{1} \\ \operatorname{maks}\left\{\sigma_{1}^{\omega}(x), \sigma_{2}^{\omega}(x)\right\} \text { untuk } x \in V_{1} \cap V_{2}\end{cases}
$$

dan 


$$
\mu^{\omega}=\left(\mu_{1}^{\omega} \cup \mu_{2}^{\omega}\right)(x)=\left\{\begin{array}{l}
\mu_{1}^{\omega}(x), \quad \text { untuk } x \in E_{1}-E_{2} \\
\mu_{2}^{\omega}(x), \quad \text { untuk } x \in E_{2}-E_{1} \\
\operatorname{maks}\left\{\mu_{1}^{\omega}(x), \mu_{2}{ }^{\omega}(x)\right\} \text { untuk } x \in E_{1} \cap E_{2}
\end{array}\right.
$$

Selanjutnya, akan dibuktikan bahwa fungsi $\sigma^{\omega}=\sigma_{1}^{\omega} \cup \sigma_{2}{ }^{\omega}$ adalah fungsi bijektif. Untuk membuktikan sifat injektif, maka harus ditunjukkan bahwa jika $u \neq v$, maka $\sigma^{\omega}(u) \neq \sigma^{\omega}(v)$ untuk setiap $u, v \in V_{1} \cup V_{2}$. Ambil sembarang $u, v \in V_{1} \cup V_{2}$ dengan $u \neq v$. Terdapat tiga kemungkinan dalam pengambilan sembarang $u, v \in V_{1} \cup V_{2}$, yakni untuk $u \in V_{1}$ dan $v \in V_{2}$, untuk $u \in V$ dan $v \in V_{1} \cap V_{2}$, dan $u, v \in V_{1} \cap V_{2}$. Jika $u \in V_{1}$ dan $v \in V_{2}$, maka

$$
\begin{aligned}
\sigma^{\omega}(u) & =\sigma_{1}^{\omega}(u) \\
& \neq \sigma_{2}{ }^{\omega}(v) \\
& =\sigma^{\omega}(v)
\end{aligned}
$$

sehingga diperoleh $\sigma^{\omega}(u) \neq \sigma^{\omega}(v)$. Jika $u \in V$ dan $v \in V_{1} \cap V_{2}$, maka

$$
\begin{aligned}
\sigma^{\omega}(u) & =\sigma_{1}^{\omega}(u) \\
& \neq \operatorname{maks}\left\{\sigma_{1}^{\omega}(v), \sigma_{2}{ }^{\omega}(v)\right\} \\
& =\left(\sigma_{1}^{\omega} \cup{\sigma_{2}}^{\omega}\right)(v) \\
& =\sigma^{\omega}(v)
\end{aligned}
$$

sehingga diperoleh $\sigma^{\omega}(u) \neq \sigma^{\omega}(v)$. Jika $u, v \in V_{1} \cap V_{2}$, maka

$$
\begin{aligned}
\sigma^{\omega}(u) & =\operatorname{maks}\left\{\sigma_{1}^{\omega}(u), \sigma_{2}{ }^{\omega}(u)\right\} \\
& \neq \operatorname{maks}\left\{\sigma_{1}^{\omega}(v), \sigma_{2}{ }^{\omega}(v)\right\} \\
& =\left(\sigma_{1}^{\omega} \cup{\sigma_{2}}^{\omega}\right)(v) \\
& =\sigma^{\omega}(v)
\end{aligned}
$$


sehingga diperoleh $\sigma^{\omega}(u) \neq \sigma^{\omega}(v)$. Jadi, fungsi $\sigma^{\omega}=\sigma_{1}^{\omega} \cup \sigma_{2}{ }^{\omega}$ bersifat injektif. Selanjutnya, misalkan fungsi untuk simpul didefinisikan $\sigma_{1}^{\omega}: V_{1} \rightarrow A_{1} \in[0,1]$, $\sigma_{2}{ }^{\omega}: V_{2} \rightarrow A_{2} \in[0,1]$, dan $\sigma^{\omega}:\left(V_{1} \cup V_{2}\right) \rightarrow A=\left(A_{1} \cup A_{2}\right) \in[0,1]$. Kemudian, akan ditunjukkan bahwa $\sigma^{\omega}=\sigma_{1}^{\omega} \cup \sigma_{2}{ }^{\omega}$ bersifat surjektif. Artinya, untuk setiap $a \in A$ selalu terdapat $u \in V_{1} \cup V_{2}$, sehingga $\sigma^{\omega}(u)=a$. Untuk $a \in A_{1}$, selalu terdapat $u_{1} \in V_{1}$ sedemikian sehingga $\sigma_{1}^{\omega}\left(u_{1}\right)=a$. Demikian pula untuk $a \in A_{2}$, selalu terdapat $u_{2} \in V_{2}$ sedemikian sehingga $\sigma_{2}{ }^{\omega}\left(u_{2}\right)=a$. Dengan demikian, terbukti bahwa $\sigma^{\omega}=\sigma_{1}{ }^{\omega} \cup \sigma_{2}{ }^{\omega}$ bersifat surjektif. Lebih lanjut, karena $\sigma^{\omega}=\sigma_{1}{ }^{\omega} \cup \sigma_{2}{ }^{\omega}$ bersifat injektif sekaligus surjektif, maka $\sigma^{\omega}=\sigma_{1}{ }^{\omega} \cup \sigma_{2}{ }^{\omega}$ bijektif. Dengan cara yang sama, akan dibuktikan bahwa fungsi $\mu^{\omega}=\mu_{1}^{\omega} \cup \mu_{2}^{\omega}$ adalah fungsi bijektif. Untuk membuktikan sifat injektif, maka harus ditunjukkan terlebih dahulu bahwa jika $\quad(u, v) \neq(c, d)$, maka berlaku $\quad \mu^{\omega}(u, v) \neq \mu^{\omega}(c, d) \quad$ untuk setiap $(u, v),(c, d) \in E_{1} \cup E_{2} . \quad$ Ambil sembarang $(u, v),(c, d) \in E_{1} \cup E_{2} \quad$ dengan $(u, v) \neq(c, d)$. Terdapat tiga kemungkinan dalam pengambilan sembarang $(u, v),(c, d) \in E_{1} \cup E_{2}$, yakni untuk $(u, v) \in E_{1}$ dan $(c, d) \in E_{2}$ maka

$$
\begin{aligned}
\mu^{\omega}(u, v) & =\mu_{1}^{\omega}(u, v) \\
& \neq \mu_{2}^{\omega}(c, d) \\
& =\mu^{\omega}(c, d)
\end{aligned}
$$

sehingga diperoleh $\mu^{\omega}(u, v) \neq \mu^{\omega}(c, d)$. Untuk $(u, v) \in E_{1}$ dan $(c, d) \in E_{1} \cap E_{2}$, maka

$$
\begin{aligned}
\mu^{\omega}(u, v) & =\mu_{1}^{\omega}(u, v) \\
& \neq \operatorname{maks}\left\{\mu_{1}^{\omega}(c, d), \mu_{2}^{\omega}(c, d)\right\} \\
& =\left(\mu_{1}^{\omega} \cup \mu_{2}^{\omega}\right)(c, d) \\
& =\mu^{\omega}(c, d)
\end{aligned}
$$


sehingga diperoleh $\mu^{\omega}(u, v) \neq \mu^{\omega}(c, d)$. Untuk $(u, v),(c, d) \in E_{1} \cap E_{2}$, maka

$$
\begin{aligned}
\mu^{\omega}(u, v) & =\operatorname{maks}\left\{\mu_{1}^{\omega}(u, v), \mu_{2}^{\omega}(u, v)\right\} \\
& \neq \operatorname{maks}\left\{\mu_{1}^{\omega}(c, d), \mu_{2}^{\omega}(c, d)\right\} \\
& =\left(\mu_{1}^{\omega} \cup \mu_{2}^{\omega}\right)(c, d) \\
& =\mu^{\omega}(c, d)
\end{aligned}
$$

sehingga diperoleh $\mu^{\omega}(u, v) \neq \mu^{\omega}(c, d)$. Jadi, fungsi $\mu^{\omega}=\mu_{1}^{\omega} \cup \mu_{2}^{\omega}$ bersifat injektif. Selanjutnya, fungsi untuk sisi didefinisikan dengan $\mu_{1}^{\omega}: E_{1} \rightarrow B_{1} \in[0,1]$, $\mu_{2}^{\omega}: E_{2} \rightarrow B_{2} \in[0,1], \quad$ dan $\mu^{\omega}:\left(E_{1} \cup E_{2}\right) \rightarrow B=\left(B_{1} \cup B_{2}\right) \in[0,1]$. Kemudian, akan ditunjukkan bahwa $\mu^{\omega}=\mu_{1}^{\omega} \cup \mu_{2}{ }^{\omega}$ bersifat surjektif. Artinya, untuk setiap $b \in B$ selalu terdapat $(u, v) \in E_{1} \cup E_{2}$, sehingga $\mu^{\omega}(u, v)=b$. Untuk $b \in B_{1}$, selalu terdapat $\left(u_{1}, v_{1}\right) \in E_{1}$ sedemikian sehingga $\mu_{1}^{\omega}\left(u_{1}, v_{1}\right)=b$. Demikian pula untuk $b \in B_{2}$, selalu terdapat $u_{2} \in V_{2}$ sedemikian sehingga $\mu_{2}^{\omega}\left(u_{2}, v_{2}\right)=b$. Dengan demikian, terbukti bahwa $\mu^{\omega}=\mu_{1}^{\omega} \cup \mu_{2}^{\omega}$ bersifat surjektif. Lebih lanjut, karena $\mu^{\omega}=\mu_{1}^{\omega} \cup \mu_{2}^{\omega}$ bersifat injektif sekaligus surjektif, maka $\mu^{\omega}=\mu_{1}^{\omega} \cup \mu_{2}^{\omega}$ bijektif.Selanjutnya, akan ditunjukkan bahwa untuk setiap $u, v \in V$ berlaku $\left(\mu_{1}^{\omega} \cup \mu_{2}{ }^{\omega}\right)(u, v)<\left({\sigma_{1}}^{\omega} \cup{\sigma_{2}}^{\omega}\right)(u) \wedge\left({\sigma_{1}}^{\omega} \cup \sigma_{2}{ }^{\omega}\right)(v)$. Jika memperhatikan asal sisi dari setiap sisi di $G^{\omega}$, maka terdapat tiga kasus berbeda yang harus diselidiki, yakni untuk $(u, v) \in E_{1}-E_{2},(u, v) \in E_{2}-E_{1}$, dan $(u, v) \in E_{1} \cap E_{2}$.

Kasus I: untuk $(u, v) \in E_{1}-E_{2}$.

Jika memperhatikan asal simpul dari setiap sisi di $G^{\omega}$ dengan $(u, v) \in E_{1}-E_{2}$. maka terdapat tiga subkasus yakni

a. untuk $u, v \in V_{1}-V_{2}$

$$
\begin{aligned}
\left(\mu_{1}^{\omega} \cup \mu_{2}{ }^{\omega}\right)(u, v) & =\mu_{1}^{\omega}(u, v) \\
& <\sigma_{1}^{\omega}(u) \wedge \sigma_{1}^{\omega}(v)
\end{aligned}
$$




$$
=\left(\sigma_{1}^{\omega} \cup \sigma_{2}{ }^{\omega}\right)(u) \wedge\left(\sigma_{1}^{\omega} \cup \sigma_{2}{ }^{\omega}\right)(v)
$$

b. untuk $u \in V_{1}-V_{2}$ dan $v \in V_{1} \cap V_{2}$

$$
\begin{aligned}
\left(\mu_{1}^{\omega} \cup \mu_{2}{ }^{\omega}\right)(u, v) & <\sigma_{1}^{\omega}(u) \wedge\left(\sigma_{1}^{\omega}(v) \vee \sigma_{2}{ }^{\omega}(v)\right) \\
& =\left(\sigma_{1}^{\omega} \cup \sigma_{2}{ }^{\omega}\right)(u) \wedge\left(\sigma_{1}^{\omega} \cup \sigma_{2}{ }^{\omega}\right)(v)
\end{aligned}
$$

c. untuk $u, v \in V_{1} \cap V_{2}$

$$
\begin{aligned}
\left(\mu_{1}^{\omega} \cup \mu_{2}^{\omega}\right)(u, v) & <\left(\sigma_{1}^{\omega}(u) \vee \sigma_{2}{ }^{\omega}(u)\right) \wedge\left(\sigma_{1}^{\omega}(v) \vee \sigma_{2}{ }^{\omega}(v)\right) \\
& =\left(\sigma_{1}^{\omega} \cup \sigma_{2}{ }^{\omega}\right)(u) \wedge\left(\sigma_{1}{ }^{\omega} \cup \sigma_{2}{ }^{\omega}\right)(v)
\end{aligned}
$$

Kasus II: untuk $(u, v) \in E_{2}-E_{1}$,

Jika memperhatikan asal simpul dari setiap sisi di $G^{\omega}$ dengan $(u, v) \in E_{2}-E_{1}$, maka terdapat tiga subkasus yakni

a. untuk $u, v \in V_{2}-V_{1}$

$$
\begin{aligned}
\left(\mu_{1}^{\omega} \cup \mu_{2}{ }^{\omega}\right)(u, v) & =\mu_{2}{ }^{\omega}(u, v) \\
& <\sigma_{2}{ }^{\omega}(u) \wedge \sigma_{2}{ }^{\omega}(v) \\
& =\left(\sigma_{1}^{\omega} \cup \sigma_{2}{ }^{\omega}\right)(u) \wedge\left(\sigma_{1}{ }^{\omega} \cup \sigma_{2}{ }^{\omega}\right)(v)
\end{aligned}
$$

b. untuk $u \in V_{2}-V_{1}$ dan $v \in V_{1} \cap V_{2}$

$$
\begin{aligned}
\left(\mu_{1}^{\omega} \cup \mu_{2}{ }^{\omega}\right)(u, v) & <\sigma_{2}{ }^{\omega}(u) \wedge\left(\sigma_{1}{ }^{\omega}(v) \vee \sigma_{2}{ }^{\omega}(v)\right) \\
& =\left(\sigma_{1}{ }^{\omega} \cup \sigma_{2}{ }^{\omega}\right)(u) \wedge\left(\sigma_{1}{ }^{\omega} \cup \sigma_{2}{ }^{\omega}\right)(v)
\end{aligned}
$$

c. untuk $u, v \in V_{1} \cap V_{2}$

$$
\begin{aligned}
\left(\mu_{1}^{\omega} \cup \mu_{2}{ }^{\omega}\right)(u, v) & <\left(\sigma_{1}^{\omega}(u) \vee \sigma_{2}{ }^{\omega}(u)\right) \wedge\left(\sigma_{1}^{\omega}(v) \vee \sigma_{2}{ }^{\omega}(v)\right) \\
& =\left(\sigma_{1}^{\omega} \cup \sigma_{2}{ }^{\omega}\right)(u) \wedge\left(\sigma_{1}{ }^{\omega} \cup \sigma_{2}{ }^{\omega}\right)(v)
\end{aligned}
$$

Kasus III: untuk $(u, v) \in E_{1} \cap E_{2}$

Jika memperhatikan asal simpul dari setiap sisi di $G^{\omega}$ dengan $(u, v) \in E_{1} \cap E_{2}$ maka hanya terdapat satu kemungkinan yakni untuk $u, v \in V_{1} \cap V_{2}$ 


$$
\begin{aligned}
\left(\mu_{1}^{\omega} \cup \mu_{2}{ }^{\omega}\right)(u, v) & =\mu_{1}^{\omega}(u, v) \vee \mu_{2}{ }^{\omega}(u, v) \\
& <\left(\sigma_{1}^{\omega}(u) \wedge \sigma_{1}{ }^{\omega}(u)\right) \vee\left(\sigma_{2}{ }^{\omega}(v) \wedge \sigma_{2}{ }^{\omega}(v)\right) \\
& =\left(\sigma_{1}^{\omega}(u) \vee \sigma_{2}{ }^{\omega}(u)\right) \wedge\left(\sigma_{1}{ }^{\omega}(v) \vee \sigma_{2}{ }^{\omega}(v)\right) \\
& =\left(\sigma_{1}^{\omega} \cup \sigma_{2}{ }^{\omega}\right)(u) \wedge\left(\sigma_{1}{ }^{\omega} \cup \sigma_{2}{ }^{\omega}\right)(v)
\end{aligned}
$$

Dengan demikian, terbukti bahwa

$$
\left(\mu_{1}^{\omega} \cup \mu_{2}{ }^{\omega}\right)(u, v)<\left(\sigma_{1}{ }^{\omega} \cup \sigma_{2}{ }^{\omega}\right)(u) \wedge\left(\sigma_{1}{ }^{\omega} \cup \sigma_{2}{ }^{\omega}\right)(v)
$$

sehingga graf $G^{\omega}$ juga merupakan graf dengan pelabelan fuzzy.

Definisi 5. Graf dengan pelabelan fuzzy pada graf dikatakan graf ajaib fuzzy jika $\sigma^{\omega}(u)+\mu^{\omega}(u, v)+\sigma^{\omega}(v)$ memiliki nilai konstanta ajaib yang sama untuk setiap $u, v \in V$ yang dinotasikan dengan $m_{0}(G)$.

Proposisi 6. Jika $G^{\omega}$ adalah graf dengan pelabelan fuzzy ajaib, maka $G^{\omega}$ setidaknya memiliki satu jembatan fuzzy.

Bukti. Misal $G^{\omega}$ adalah graf dengan pelabelan fuzzy ajaib. Pilih sebuah sisi $(x, y)$ yang memiliki label tertinggi dari himpunan $V$. Dengan demikian, untuk setiap simpul $u, v \in V$ pasti memenuhi $\mu^{\omega}(u, v)<\mu^{\omega}(x, y)$. Kekuatan keterhubungan antara simpul $x$ dan $y$ adalah

$$
\begin{aligned}
\mu^{\omega^{\infty}}(x, y) & =\sup \left\{\mu^{\omega^{1}}(x, y), \mu^{\omega^{2}}(x, y), \mu^{\omega^{3}}(x, y) \ldots \mu^{\omega^{k}}(x, y)\right\} \\
& =\sup \left\{\begin{array}{l}
\mu^{\omega}(x, y), \sup \left\{\mu^{\omega}\left(x, y_{1}\right) \wedge \mu^{\omega}\left(y_{1}, y\right)\right\}, \ldots, \\
\sup \left\{\mu^{\omega}\left(x, y_{1}\right) \wedge \mu^{\omega}\left(y_{1}, y_{2}\right) \wedge \ldots \wedge\left(y_{k-1}, y\right)\right\}
\end{array}\right\} \\
& =\mu^{\omega}(x, y)
\end{aligned}
$$

Selanjutnya, jika sisi $(x, y)$ dihilangkan sehingga $\mu^{\omega}(x, y)=0$. Misal kekuatan keterhubungan antara simpul $x$ dan $y$ adalah $\mu^{\prime \omega^{\infty}}(x, y)=\mu^{\prime \omega}\left(u_{1}, v_{1}\right)$ untuk suatu $u_{1}, v_{1} \in V$, maka 


$$
\begin{aligned}
\mu^{\prime \omega^{\infty}}(x, y) & =\mu^{\prime \omega}\left(u_{1}, v_{1}\right) \\
& <\mu^{\omega}(x, y) \\
& =\mu^{\omega^{\infty}}(x, y)
\end{aligned}
$$

Dengan demikian, kekuatan keterhubungan antara simpul $x$ dan $y$ menjadi lebih kecil dari sebelumnya atau $\mu^{\prime \omega^{\infty}}(x, y)<\mu^{\omega^{\infty}}(x, y)$. Karena penghapusan sisi $(x, y)$ pada graf $G$ mengurangi kekuatan keterhubungan antara simpul $x$ dan $y$, maka sisi $(x, y)$ adalah jembatan fuzzy. Dengan demikian, terbukti bahwa untuk sembarang graf ajaib selalu terdapat minimal satu jembatan fuzzy.

\section{KESIMPULAN DAN SARAN}

\subsection{Kesimpulan}

Berdasarkan hasil dan pembahasan, maka diperoleh kesimpulan bahwa pelabelan fuzzy merupakan fungsi bijektif yang memetakan semua simpul dan sisi pada graf dasar $G^{*}$ ke himpunan $[0,1]$ sedemikian sehingga label sisinya selalu lebih kecil dari minimum kedua simpul yang bersisian dengannya. Gabungan dari dua graf dengan pelabelan fuzzy merupakan graf dengan pelabelan fuzzy jika semua label simpul dan sisi di kedua graf tersebut berbeda. Graf dengan pelabelan fuzzy $G^{\omega}(V, E)$ dikatakan graf ajaib fuzzy jika $\sigma^{\omega}(u)+\mu^{\omega}(u, v)+\sigma^{\omega}(v)$ memiliki nilai yang sama untuk setiap $u, v \in V$. Selalu terdapat jembatan fuzzy pada sembarang graf ajaib fuzzy.

\subsection{Saran}

Dari hasil penelitian ini, dapat dilakukan penelitian lebih lanjut mengenai graf ajaib fuzzy, menentukan formulasi konstanta ajaib fuzzy pada beberapa graf khusus, serta membahas aplikasi dari pelabelan fuzzy pada sebuah graf. 


\section{DAFTAR PUSTAKA}

Bede, B. (2013). Mathematics of Fuzzy Sets and Fuzzy Logic. New York: Springer.

Gani, A. N. dan Subahashini, A. R. (2012). Properties of Fuzzy Labeling Graph. Applied Mathematical Sciences. 6(70):3461-3466.

Gani, A. N. Akram, M. dan Subahashini, A. R. (2014). Novel Properties of Fuzzy Labeling Graphs. Journal of Mathematics. 375135.

Sunitha, M. (2001). Studies On Fuzzy Graphs. Cochin: Cochin University 